\title{
Practices and People
}

\author{
Ted Schatzki \\ University of Kentucky - Estados Unidos da América do Norte \\ schatzki@uky.edu
}

\begin{abstract}
A perennial issue in social thought is the relationship of people to enveloping social phenomena such as structures, institutions, and systems. The present essay explores this relationship through the lens of practice theory. Theories of practice have said much about practices, a type of enveloping social phenomena, but relatively little about people. ${ }^{i}$ This general inattention probably has something to do with the fact that theorists of practice deny that they are individualists. The neglect is nonetheless surprising, for people are everywhere in the plenum of practices. The present essay aims to help address this situation, offering a way of thinking about practices and people according to which these two phenomena are equally real while mutually dependent and co-responsible for social life.
\end{abstract}

Keywords: practices, people, practice theories, social.

\section{General Considerations}

Section one first explores the general idea that people are everywhere in the plenum of practices. It then explains why I am talking about people and not about individuals, subjects/subjectivity, or the personal. The section concludes with a sketch of my general understanding of the relationship between people and practices. The following section explores specific facets of this relationship.

The plenum of practices is the entirety of the linked practices and material arrangements that exist at a given moment or period of time. For some time now, the plenum has embraced bundles and constellations of bundles that crisscross the globe and extend a short way under the earth and into space. 
Practice theory is hardly a unified stream of thought. Despite this, one idea that just about all such theories espouse is that practices comprise actions, or activities. This is true of the views of Bourdieu, Giddens, Taylor, Reckwitz, Gherardi, Kemmis, and myself and true in modified form of those of Shove and her associates. Of course, these theorists conceptualize action/activity differently and propound disparate ideas about what else, in addition to actions/activities, compose practices. These differences notwithstanding, they concur, further, that the actions/activities that compose a practice are performed by multiple people (they are disinterested in the issue once debated by analytic philosophers of whether individual people can have their own practices). Some practice theorists add that certain actions that compose a given practice are performed by entities other than people or humans. I set this idea aside because the topic of this paper is the conjunction of people and practices, and almost none of the nonhumans that theorists have in mind when they claim this are candidates to be people.

Because people perform actions, in particular, the actions that compose practices, practices presuppose people: no people, no practices. However, the relationship between people and practices goes beyond this, as can be gleaned from the fact mentioned above that practice theorists deny that they are individualists. The claim that people perform the actions that compose practices could be taken as implying that any given practice is an abstraction that gives a name to, and thus groups together, particular episodes, that is, actions, in the lives of distinct individuals. If this were true, practices would consist in, be nothing but, the thereby grouped together actions. On this view, all there would be to practices (and to social phenomena more broadly) is collections of individuals' actions and of other features of these individuals that bear on their actions.

Practice theorists' understandings of the claim that people perform the actions that compose practices do not carry this implication. For them, practices are just as real as people are: both exist making a difference to how the world is. If anything, some practice theorists are tempted by the neo- and post-structuralist idea that practices are more real than people are and that people are a kind of distillate or condensation from practices (e.g., the idea that people are compendia of subject positions from diverse discourses, Laclau \& Mouffe, 1985). Most practice theorists, however, resist this idea. For them, people are always 
more than whatever of them derives from the practices in which they participate: they are always more than participants alone. I will return to this thought in section three.

The equal reality of practices and people can be conceptualized in the following way. Practices comprise the actions of different people. At the same time, each person has his or her own life. For present purposes, I construe a human life as composed of the sequences of sometimes overlapping life conditions (actions, states of consciousness, emotions, conative and cognitive states) that belong to a given person, as expressed in his or her bodily doings and movements and contextualized in the worldly situations through which he or she lives (see Schatzki, 1996; cf. Dreier, 2007). More tersely stated: a life consists in the bodilyexpressed and situationally-constituted sequences and durations of its owner's actions and mental states. Note that this conception of a life treats people as that to which actions and other life conditions as well as bodily states and states of situatedness are ascribed (cf. Strawson's, 1959 account of persons as basic particulars). A life, consequently, comprises sequences of actions among other things. In fact, it comprises sequences of actions, at least practically all of which are at the same time components in some practice(s) or other.

Two different basic ordering principles of action are at work here (cf. Reckwitz's, 2006 distinction between life forms and practice/discourse complexes). Actions are components of a practice by virtue of expressing elements of the practice's organization. Practice organizations are thus one organizing principle for action. Actions are also components of particular people's lives. People are thus a second organizing principle for action. Practices and people are distinct ordering principles, neither of which can be reduced to the other. A given action is at once a component of some practice and a part of some life. It is at once performed by someone and part of a manifold of actions performed by different people that is governed by a common organization. So both persons and practices exist. Indeed, neither can exist without the other. No people no practices; but, equally, no practices no people. As will be discussed below, people come to exist by virtue of - to state matters most generally-humans participating in practices.

For anyone who believes in what might be called, echoing Heidegger, the equifundamentality of practices and persons, the nature of the relationship between practices and persons is a key issue. Something was just said about this relationship: people 
perform the actions that compose practices, and practices are the context in which people come to be. But there is much more to be said.

Before continuing, I want to reflect on use of the concept of person (people) to designate that whose relationship to practices is presently at issue. Other concepts that might be used in this context are individual, subjectivity and subject, and the personal. I use "individual" to mean particular person. The concept of an individual has well-known connotations in ethical and political thought, but in using the concept I make no use of the idea that individuals, say, have rights or are autonomous. The term is also common in those areas of the social sciences that draw on rational choice theory and its cognates and philosophical bases. Again, I do not build into the notion of the individual any conception of rationality and choice. An individual is simply a particular person, and individuals in the plural are sets of particular people. Of course, "people" is rich and complex in the way "individual" is arid and abstract. That is why I prefer "people." But issues about the relationship between people and practices are equally issues about the relationship between individuals and practices.

By contrast, I do not construe issues about people and practices to be issues about subjectivity, or subjects, and practices. Subjectivity is a vexed concept, and this is not the place to plumb its enigma. To me, subjectivity is something like the inside of a person's experience, thus just one sort of mental phenomena. This inside, however understood, is one of many features of people that might be tied to practices. Indeed, the relationship between subjectivity in this sense (there are others) and practices is a fascinating area of investigation, about which little has been written. But much more of people than subjectivity alone is tied and pertinent to practices. So a richer, and more salient, domain of study is the relationship of people to practices. As for the term "subject," it is true that "subject" means more than simply that which has or enjoys subjectivity. Indeed, it can be used in a way roughly coextensive with "people." For many thinkers conversant with modern philosophy, however, the term carries a thicket of connotations that makes it inadvisable, and possibly misleading, to use. ${ }^{\text {ii }}$ At the same time, the term can simply connote subjection and subjectivation, which name important dimensions of the coming to be of people (e.g., Alkemeyer, Busch, \& Michaeeler, 2016). It is helpful, therefore, to keep the term "subject" around to capture these aspects of personhood. 
The term "personal," finally, is polysemic. It can connote, among other things, a person's zone of intimacy and familiarity ("personal care"), what ain't nobody's business but one's own (as in private versus public), or the features that belong to a particular life and no others (e.g., his personal attributes). "Personal" can also be more or less synonymous with “a particular person's," with no implications as to uniqueness (e.g., someone's personal opinion about something); in this latter usage, the personal is coextensive with the individual. As with subjectivity, the relationships to practices of the phenomena denoted by the different senses of "personal" are possible topics of investigation. However, these phenomena hang together with a broader range of phenomena, and their relationships to practices are tied to features of this wider domain. The terms "people" and "people's lives" point toward that wider domain.

My basic understanding of the relationship between practices and people takes the following form.

1.Bundles of practices and material arrangements form a basic reality. This reality is not all there is to or all that bears on human life. But it is a reality, nonetheless, with which-on the principle that truths are compatible with one another-the remainder of human life must be compatible. The brain, for instance, bears on social life but is not encompassed as such in practice-arrangement bundles. Consequently, its operations must be compatible with the existence of bundles. Note that it is for the domain of social thought that bundles constitute a basic reality. The claim, say, that social phenomena transpire in the plenum of practices does not imply that practices and bundles are basic in cognitive brain science, where today such phenomena as neural nets and mirror neurons take central stage. Conversely, bundles must be compatible with the truth of brain processes-whatever that turns out to be (for thoughts on this matter, see Turner, 2002).

2. People's lives proceed on the background of bundles. The latter are a state of the world, given which individual lives proceed as they do. That is, bundles are always already there when humans begin to participate in them and then carry them on, regardless of how much bundles evolve as people do so. The giveness of bundles helps defines the situatedness of individual people in the world.

3. Many phenomena occur as part of or in the context of bundles. For something to occur in the context of a bundle is for it to occur dependently on that bundle. An 
example of something that occurs as part of bundles is interactions: the particular actions that compose particular interactions are components of one or more bundles, subject to the organizations of the practices involved. Examples of things that occur in the context of bundles are experiences, the dissemination of knowledge and ideas, learning, and the constant adjustments that people make as they ongoingly act. Experiences, for example, occur in the context of bundles since people have them while they perform actions that are part of the bundles involved. Similarly, for learning to take place within bundles is for people to acquire knowledge, judgment, character traits, and self-understandings (among other things) as they perform-or as a result of their performing-actions that help compose bundles. People's lives, too, proceed, not just amid (as in 2.), but also within and as part of bundles.

4. In addition, however, people's lives proceed through bundles. Interrelated bundles are spread out across the face of the earth. People move about on the earth through this given reality, perpetuating as well as transforming it. iii The sequences of actions that help compose their lives are components of linked contiguous bundles.

This proceeding through has multiple dimensions. To begin with, people proceed amid the three dimensional layouts of the material arrangements that are part of bundles. The physicality and geometry of these arrangements always set real constraints on action and must be accommodated (even while they are being altered). People likewise proceed amid arrays of places and paths that are anchored in these arrangements, where a place is a place to $\mathrm{X}$ and a path is a way from one place to another. Which places and paths are anchored where depends both on which practices are carried on at particular arrangements and on features of individuals such as ends, projects, emotions, and beliefs. People, moreover, are sensitive to the place-path arrays that are distributed across the material arrangements amid which they proceed; some actions, for example, are performed at particular entities because a place to perform that action is anchored there (e.g., sleeping in a bed). As people go through their day and carry on the practices that others do, the spatialities of their lives interweave: they act at common, shared, and orchestrated places and paths (see Schatzki, 2010; places/paths are orchestrated when different places and paths are nonindependently anchored for different people at the same material arrangements). 
Practices exhibit not just interwoven activity spatialities, but also interwoven activity temporalities (the constitutive teleological and motivational dimensions of activity; see Schatzki, 2010). Spatiality and temporality also connect: practices exhibit interwoven timespaces. These interwoven timespaces are the common, shared, and orchestrated timespaces of participants in given practices.

In addition, people, as they carry on this and that practice, are sensitive to the normative organization of these practices and take these organizations into account in their activity (see below).

All told, people's lives proceed as part of particular bundles amid these bundles' geometric material arrangements, sensitive to both the place-path arrays anchored there and the normative organizations of the bundles' practices. The timespaces of their lives also help compose the interwoven timespaces of these bundles. Collectively, these facts constitute what it is for the activity sequences of people's lives to proceed through the reality of linked bundles that is spread out across the globe.

I wrote that people perpetuate and transform the bundles they join. This observation suffices to counter any impression that people, though active, merely accommodate themselves, or are simply subjected, to the indomitable reality of linked bundles. Individuals do, of course, unavoidably accommodate themselves to this reality, and in doing so they-their knowledges, personalities, proclivities, hopes, ends etc.-are molded. Conversely, however, bundles are labile and altered through human activity, though not exclusively through this. The mutual dependence between activity, on the one hand, and practices or fields thereof on the other is well-known to readers of Giddens (1979) and Bourdieu (1990). The sort of mutual dependence just expounded converges best with Archer's (1995) view that the mutual dependence is stretched out over time and not simply reconsummated in the duration of each particular activity.

\section{Dimensions of the Relationship}

The relationship between practices and people is far too complex for it, or any of its aspects, to be adequately charted here. This relationship also bears on a wide range of subject matters, especially ones in philosophy of mind and action, the humanist corners of 
psychology, and the social sciences. I will say nothing about these implications presently. The current section will instead highlight a few crucial aspects of the relationship.

Elsewhere (Schatzki, 2010) I have described how the organizations of practices circumscribe the actions of those participating in them. Practice organizations accomplish this because they are normative in character, and people are sensitive to normativity. By "normativity" I mean what is acceptable and enjoined (prescribed, expected). I do not suggest that people always do what is acceptable or enjoined. I claim only (1) that people know that they are supposed to do what is acceptable and enjoined and are generally aware of which actions qualify and (2) that in most situations they do something that is acceptable or enjoined, though they also sometimes act contrary to, in defiance of, or in the hopes of escaping etc. norms. The fact that humans sanction violations of normativity in all sorts of ways, from subtle expressions of disapproval to floggings and hangings, is part of the story of why humans are sensitive to normativity. The ubiquity of normativity is presumably another part of the story, as is, plausibly, evolutionary selection.

Because practices are normatively organized, people who participate in given practices tend to perform actions that are acceptable or enjoined in them. Some of these actions satisfy rules-explicit directives, instructions and admonitions-that are at work in these practices. Others make sense to perform in pursuit of tasks, projects, ends, and combinations thereof that are acceptable or enjoined in the practice. Still others are animated by emotions that are acceptable or enjoined there (see Schatzki, 2010, chapt. 3). Emotions, in addition, call out particular affects in people (see Reckwitz, 2017). Reckwitz notes, for instance, that the emotion of love that developed in a bundle of practices emerging in the late $18^{\text {th }}$-century calls out such affects in people as physical desire, longing, and the pain of unrequited love. More generally, Reckwitz avers, practices and constellations of practices carry regimes of affects. The affects making up these regimes both motivate people to carry out the actions that compose the practices involved and focus people's attention on, among other things, objects pertinent to the practices. As a result, emotions are a medium through which people and practices connect (see Weenink \& Spaargaren, 2016 and below).

Other aspects of practice organization also bear on action. General understandings, which are general senses of things that suffuse bundles, can, like emotions, affect what ends, 
motivations, projects, and tasks a person pursues. Examples of such understandings are the nobility of teaching, the sense of which is active in many teaching practices worldwide despite how beleaguered teachers can be, and the sanctimony of worldly work, the sense of which animated the industrial practices of the American millennial group the Shakers (Schatzki, 2002). A final aspect of practice organization, practical understandings, likewise inform action. Practical understanding is knowing what bodily doings and saying to perform in order to carry out a desired action (e.g., moving one's arm back and forth in order to wave). The normativized practical understandings carried in practice organizations secure the performance of particular bodily doings and sayings; they also help ensure mutual intelligibility among practitioners.

A second key aspect of the relationship between people and practices concerns learning. By "learning," I mean the acquisition by individuals of such items as knowledge (propositional and practical), feelings, aesthetic judgment, reflective powers, selfunderstandings, and character traits such as politeness and prudence. ${ }^{\text {iv }}$ As noted above in passing, learning takes place on the background of bundles (cf. Dreier, 2009). This is because learning, however it occurs, takes place as people perform actions (or as a result of their doing so). The actions involved can be performed in many contexts, for instance, in classrooms, at work, in athletic facilities, as part of informal conversations or drawn-out formal proceedings, and they can be of many types, for instance, reflecting, reading, watching, asking, attempting, repeating, and so on. Indeed, learning can in principle take place when a person performs an action of practically any sort. Since, furthermore, in performing almost any action a person is at the same time carrying on specific practices, whatever learning occurs when a person acts takes place while he is carrying on some practice or other, thus within some bundle or other. In addition, features of the bundles in which learning takes place are relevant to what is learned. The doings and sayings performed, the subject matters of the sayings, the projects and tasks pursued, the material arrangements including the texts and electronic devices present, what others are doing, and what is going on in settings - these sorts of things make a huge difference to what is learned. Learning takes place within bundles in the senses (1) that it happens while people carry on the bundle's practices (or as a result of their doing so) and (2) what is learned is keyed to components of the bundle, including actions, texts, and visual displays. 
Learning is central to what and who anyone is. "What" a person is is twofold. It is, first, the type of person someone is (e.g., baker, American, good father) and, second, that person's features. By "who" someone is I mean that person's identity. Identity is a contentious matter, and for present purposes I will treat it as a person's understanding of what he or she is; identities foisted on but rejected by someone are part of what she is but not who she is. Because learning is central to what and who anyone is, becoming someone (ontogenesis) unfolds within the bundles through which a person lives (cf. Billett, 2001, 2006, 2009). This fact makes components, features, and relations among bundles crucial to ontogenesis: the coming-to-be of the people who perform the actions that compose practices unfolds within already existing practices (bundles) whose constituent actions are primarily performed by other people and eventually also by the people who are developing. This is a crucial dimension of the relationship between people and practices. Note that I am not claiming that learning is becoming. Learning contributes to becoming since what someone is constantly expands through learning. But more than learning alone-e.g., contingent events, the actions of others-contributes to becoming. Becoming a particular individual also involves the development of particular self-understandings, to which learning, but not learning alone, contributes.

A prominent way of thinking in social theory conceptualizes human activity as situated (Schutz, Popper, Garfinkel, Goffman, Suchman). The term "situated" can be a stand-in for the concept of context, and many different conceptions exist of the contexts in which people act. The term can also imply that people primarily and ubiquitously proceed in a particular kind of context, namely, situations. Theorists of situations treat situations as comprising the states of the world in response to, in light of, or in the context of which people proceed as they do.

Talk of lives proceeding through bundles parallels talk of people acting in situations. In each case, what people do is tied to something that surrounds them or in which they are immersed: a situation, a bundle. The difference is that situations comprise states of the world that directly bear on what people do (that in response to which or in light of which people act), whereas bundles are a given, more complete reality or state of the world amid which they proceed. Nonetheless, features of bundles, and occasionally whole bundles, though rarely bundles as such, figure as situations or as elements thereof. In fact, bundles, 
as wider states of the world, provide most of the elements out of which situations consist: actions, interactions, events, normativities, material arrangements, objects, and changes in these matters. So, the plenum of practices contains situations. This is true even when that in the light of which a person acts exists far away from her in space and time. Note that which features of the plenum constitute a particular situation is relative to the individual in it, her desires, hopes, beliefs, and so on. This entails that different people proceeding through the same bundles often find themselves in different situations given their divergent desires, hopes, beliefs, and the like.

Much of the above suggests that people-actions, minds, learning, becoming, situations-are passively shaped by bundles. The fact that situations depend on individuals indicates that people are not just on the receiving end in the relationship to practices: they, too, contribute to the relationship. A second phenomenon that depends partly on practices and partly on people is people taking up and carrying on the same practices differently. Consider the practices of doctors. As Dall'Alba (2009, Dall'Alba \& Sandberg, 2010) has well documented, there are different ways of being a doctor, for instance, a more scienceoriented way of being in which the doctor maintains a distance from the patient and a more humanistic-oriented way that puts greater emphasis on caring and talking. According to Dall-Alba, a way of being encompasses acting, knowledge, and being (identity, who someone is). Her point is that professional practices admit different ways of being enacted that involve different ways of being the professionals involved. It is a fair surmise that this phenomenon is not confined to professional practices and often exists when participants in particular practices occupy particular roles and positions.

In the terms of my account of practices, different ways of carrying on a set of practices and being someone of a given sort in them comprise partially overlapping and partially divergent combinations of doings and sayings, same as well as different end-project-task combinations, same and different emotions, some of the same, but also divergent knowledges, especially know-hows (e.g., how to draw out a patient's fears), the same institutional rules alongside divergence in less formal rules, and partially divergent selfunderstandings in the form of general understandings about what it is to be a physician. No definable limits exist as to how many ways of carrying on given practices and being a particular professional in them can be admitted by the practices, though practices often 
carry a relatively small number that are exemplified by particular individuals who serve as archetypes for others to learn from and emulate. Most important, these ways of carrying on/being an $\mathrm{X}$ are properties of the practices themselves. It is true that these ways are exemplified by particular individuals and that it is through individuals' actions that ways of being come about, persist, and evolve. But regardless of how it has come about, any way of proceeding that qualifies as a way of carrying on certain practices or as way of being an $\mathrm{X}$ in them is part of the organization of the professional practices involved. It has become an acceptable or prescribed possibility carried in these practices. To quote Dall'Alba (2009, p. 32), "social structures and traditions of practice...provide openings for multiple ways of being professionals in our contemporary world." Of course, someone might have a unique style, a unique way of being a doctor, that no one emulates. But this style, too, is contained in the organization of doctoring practices. For regardless of the particular ways of being a doctor that they themselves embody, doctors recognize other ways of being a doctor, including idiosyncratic ones-and it is recognition by participants in the professional practices of medicine that at once certifies ways of acting as a way of being a doctor and makes these ways part of practice organization (for discussion of the role of recognition in becoming a particular person, see Alkemeyer \& Busch, 2017). Of course, conflict can arise about whether particular ways are acceptable or not, whether someone who acts that way is really a doctor. Such conflict, however, is part and parcel of the normal normative development of bundles. Different ways of carrying on medical practices and being a doctor are still features of the bundles themselves.

A facet of the multiplicity of these ways is that individuals are partly responsible for which ways of carrying on practices and being professionals in them they take up. A medical intern, for instance, can partly through her actions become one sort of doctor rather than another. She can prescribe certain treatments or tests rather than others, give patients more or less time to talk, emulate one particular senior physician rather than another, take advantage of certain possibilities or opportunities rather than others, and so on. Through these actions, she can slowly come to be a doctor of one sort rather than another. Of course, agency is not solely responsible for such developments. In addition to practices carrying limited repertoires of ways of being professionals in them, peer, professional, and other types of pressure might favor particular alternatives, and becoming a particular version of a 
certain type of person can occur unawares to someone. Yet, agency has a role to play in this process: interns' awareness of the alternatives and of divergences in colleagues' ways of being bespeaks the significant role it can play.

Agency plays a much bigger role in practices than simply helping to determine how people carry out practices and which ways of being persons of certain sorts they take up. In this context, the word "agency" can be heard in at least three ways. First, "agency" can mean acting; a person's agency is her activities. Agency in this sense is essential to practices, for practices do not exist independently of people acting. "Agency" can mean, second, choice, choosing among options. The relation of choice to agency in the first, event sense is contentious. A third notion of agency is effect on the world: to speak of the agency of some group, for instance, is to speak, not of the actions that members of the group took or the choices they made, but of the difference that their actions made to social affairs. Similarly, to say that someone was denied agency is to say, not that she could not do anything or make any choices, but that she was unable to effect or change social affairs, that is, to perform actions and make choices that made a relevant difference to how things are.

The second and third senses of agency are invoked by the claim that people are partially responsible for how they carry on practices, or as Dreier (1999) puts it, that people are responsible for composing and structuring their "modes of participating in practices:" how they carry on or participate in practices is something that they can partly choose and partly effect through their actions. This idea is connected to the further thesis that people are responsible for the conduct of their own lives through practices (Dreier, 1999, 2007). When, meanwhile, agency is said to contribute to learning, "agency" is primarily used in the third of these senses. Agency in the sense of doing always indirectly contributes to learning in the sense that whatever learning takes place while someone is awake takes place while she is doing something. Agency is more directly involved in learning, however, when what is learned (and what is not learned) partly depends on what a person does (see Billet, 2001, 2006, 2009). Two people witnessing the same events will learn different things by virtue of how they act toward these events - what they pay attention to, what they watch, what they listen to, what they infer etc. (paying attention, watching, listening, and inferring are all activities). Whereas one person might learn how certain people interact, another might learn about the events they discuss. Similarly, what someone learns in a classroom rests, 
among other things, on such matters as what she pays attention to, how hard she tries to accomplish something, whether she cooperates with her peers, whether she gives up easy when stymied, and so on. Even so allegedly an automatic process as imitation is neither automatic nor effortless, but requires various degrees of effort, determination, attention, repetition, and the like. Generally speaking, the world provides people endless occasions and affordances for learning, but what people learn partly depends on whether and how they act on those occasions and respond to these affordances.

Similarly, when it is claimed that people help determine what happens or changes in social life the third sense of agency is invoked. This is obviously a large topic, and theorists disagree about the role of action in the dynamics of social life. The present point, however, is that whatever responsibility people's action do bear for the emergence, perpetuation, and dissolution of bundles is one facet of the relationship between practices and people. It is misleading, consequently, to call people "carriers" of practices. This way of speaking portrays people as passive in relation to practices and obscures the contributions they make to practice dynamics (on these contributions, see Schatzki, 2013, 2016).

One final facet of the relationship between people and practices is that emotions mediate between them. Emotion (and mood) is more or less omnipresent in human existence. It is one dimension of existence by virtue of which things matter to people in particular ways. Fear of bears, for instance, makes bears something to stay away from, just as joy transforms how most of what a person encounters or considers matters. How people act partly rests on what and how things matter to them. Consequently, being in certain emotions or moods can result in a person performing certain actions and-since practices and bundles are among the indefinitely many sorts of thing that can matter-participating in certain practices (cf. Weenink \& Spaargaren, 2016). For example, someone who is fearful of bears might take elaborate precautions when taking a hike in bear country. Similarly, joy might result in someone performing diverse acts of kindness and consideration toward others at work. In these two cases, emotions/moods lead a person to perform certain actions, or to pursue certain combinations of ends and tasks, that are contained in the teleoaffective structures of particular practices. If fear of bears leads someone to sit in the car reading instead of hiking, the emotion is responsible, not just for what action she performs, but also for which practices she carries on. In this way, a person's emotions help 
determine the sequence of actions she performs and which practices she carries on. It is worth noting that teleology likewise helps determine this: practically everything a person does is done in pursuit of particular ends (see Schatzki, 2010). Not fear of bears, for instance, but dogged dedication to personal safety might result in someone staying in the car reading instead of hiking. In fact, a person's ends play a more central role than do her emotions in determining the sequences of actions she performs and some of the practices she takes up.

People do not have emotions in a vacuum. Emotions are tied to the situations in which people act, thus to the practices and bundles through which they proceed. Weenink and Spaargaren (ibid.) articulate a parallel idea in claiming that emotional energy à la Collins (2004) is an emergent property of practices. What they mean is that some of the positive or negative emotional charges that people receive through interacting with other people or entities can occur only within the particular bundles in which these interactions take place. In the absence of these practices (bundles) and the situations/interactions that occur in them, these emotional charges would not occur. More broadly, the emotions people undergo are tied to the bundles in which they are involved and the situations, happenings, and objects they encounter there. Hence, just as emotions lead people to carry on particular practices, it is within particular practices and bundles that people experience particular emotions. Something parallel obtains vis-à-vis teleology. Many of the ends that people pursue they are directed to by virtue of carrying on particular practices. No one, for instance, would seek to win a football game if they were not carrying on football practices. Weenink and Spaargaren also point out that emotions help link bundles. For instance, the emotional valence of a circulating thing-say, a patriotic or cult symbol or an image of a poignant incident-links the bundles through which it circulates by instigating commonalities such as common points of attention, common ends, common feelings etc. Circulating objects can also transmit emotional energy among bundles (consider, for instance, videos of public events gone viral). 


\section{People Outside Bundles}

The discussion in the previous section examined how people-minds, actions, learning, becoming someone, and situations-are molded both by and on the background of bundles and their features. It also considered how aspects of individuals-agency, emotions, teleology-affect bundles and how people relate to them. Clearly, people and practices are deeply interdependent. This situation entails that many, if not most, phenomena that transpire as part of or dependently on practices are the joint product of people and practices. Examples are interactions, mutual intelligibility, the dissemination of knowledge and ideas, and sense as well as aesthetic experience. Indeed, social phenomena generally, consisting or rooted in slices or aspects of the plenum of practices, are such joint products. Not all features of individuals, however, derive from participation in bundles. People are not merely practitioners who take form via participation. Nor is all that is of significance for social theory about people tied to their being practice-molded practitioners. Supposing otherwise parallels an error committed by a line of post- and neopoststructuralist thinkers who have theorized individuals as collections of subject positions, as crossing points of discourses (or of practices), or as nodes in relations (e.g., Laclau \& Mouffe, 1985; Reckwitz, 2002; Gergen, 1995).

An example of a feature of people that is not a product of participation in practices is the continuity of a life. As explained, a person's life is composed of actions and other conditions of life, expressed in bodily activities and tied to worldly contexts. The continuity of a life centrally lies in the fact that, so long as a person is awake, she or he is doing something. Activity, in other words, is continuous. A person is also always in some state of consciousness and emotion or mood, and these life conditions (like others) are continually expressed in what people do and say. It is true that, like the contents of her life conditions, what it is that, on any occasion, a person does in acting is tied to practices and bundles. But the fact that lives are continuous in this way is not so tied: it is neither a product of participation in practices nor a feature of being a practitioner as such. Perhaps it can be explained through bodily physiology and metabolic processes.

A parallel example is the fact that people are emotional creatures. Emotions are deeply imbricated in conduct, in the organizations of bundles, in connections between people and 
practices, and in the interwoveness of bundles in the plenum of practices. What's more, the emotions people undergo are bound up with the practices they carry on or are exposed to. But the fact that people have emotions is not a product of participation in practices. Instead, emotion seems to be a basic feature of human lives with which the edifice of practices and bundles is interlocked. ${ }^{v}$ Some emotional swings and depths likewise do not depend on the practices people carry on. Although emotions are clearly keyed to and triggered by events in the world, the extreme swings that some people undergo, like the severity of moods such as depression, as well as the timing of the onset and dissipation of strong emotions and moods, only sometimes track what is going on in the world or the particular bundles and sequences thereof in which people participate. There is clearly an organic component to these phenomena, as generational studies and lived family histories confirm. Whether this organic component somehow coordinates with bundles is an issue that transcends the scope of this paper.

I am not sure whether similar comments should be made about that sensitivity to normativity, in the absence of which normativity would have no purchase on human lives. On the one hand, practices as I conceive of them-normatively governed manifolds (see Rouse, 2001)—could not exist in the absence of this sensitivity. It is plausible, furthermore, to give an evolutionary explanation of the existence of this sensitivity. On the other hand, it is not implausible that this sensitivity develops as a person is incorporated into bundles on the basis of other fundamental dimensions of human existence, themselves perhaps the product of evolution. An example of such a further dimension is the deference-emotion system centered on shame discussed by Scheff (1988). Recognizing the role of normativity in social life does not require resolution of this issue; understanding the historical development of social life, however, does.

Another feature of people independent of participation in practices is the quality, depth, and completeness of any given individual's learning of a subject matter. As discussed, agency contributes to learning, and all learning takes place within bundles. Neither agency, immersion in bundles, or their combination, however, fully determine how much of some subject matter a person learns or how well he does so. Similar people placed in similar circumstances learn to different breadths and degrees, a fact about which 
considerable research seeks illumination-with only limited success. It is clear that something more about people at least helps make a difference.

It is likewise clear that some dimensions of bodily being swing free of bundles. The basic anatomy of the body is an example, as is the functional organization of the brain and the basic construction of bones and tissue. Other features of bodies clearly reflect, coordinate with, or derive from participation in bundles. Wear and tear on muscles and joints, thickened arteries, some cancers, and bulging muscles are obvious examples often in the news. Well-developed forms of coordination among the skeletal, muscular, and nervous systems (e.g., athletes) is another example, whereas tattoos, piercings, and hair color provide examples of an entirely different sort. Other examples are a little more hypothetical. It is eminently plausible but still evidentially speculative to claim that participation in practices results in brains being wired in particular ways (see Roepstorff, Niewöhner, \& Beck, 2010). It is also plausible, though again still speculative, to aver that participation can leave an epigenetic effect in the genome (Maller, 2017). And it is imaginable, and widely depicted and discussed in science fiction and philosophy, that the bodies of humans or their successors will one day largely be artificial, the product of particular practices.

One last aspect of human life that I want to mention in this context is the indeterminacy of action. Action is indeterminate in the sense that, prior to acting, it is not fixed, settled, or necessitated what a person does and why. Whatever he or she does is done for an end(s) and motivated by something or other, but which end(s) and what motivating something or others are responsible for the act are settled only with the act itself (in fact, they are dimensions of the act-see Schatzki, 2010). The indeterminacy of action is not a product of participation. Like continuity and emotion as dimensions of human existence, it is a basic fact about human life. There is always, fundamentally, an indeterminacy to what a person does, the ends and projects he pursues, and that in response to or in the light of which he acts.

\section{Don't Slight Practices}

In the broader landscape of social theory, it is not people who are in danger of being slighted. The hallmark of the most dominant family of social ontologies (individualism) is 
that social phenomena-including social practices-are constructions of or out of individuals, their properties, and maybe also relations among them. Social ontologies of this type hold that people are empirical, causal realities and that practices are inert abstractions. These ontologies also deny substantial reality to all other putative social things that theorists over the decades have imagined: structures, discourses, societies, and the like. This position obviously opposes an ontology such as my own that holds that practices are just as real as people are: it cannot recognize the sort of relationship between practices and people examined in this essay.

Given the historical dominance of individualism, I want, in this final section, to examine a very innovative contemporary version of it that explicitly criticizes regularity conceptions of practices (e.g., Bourdieu, Reckwitz): Laurent Thevenot's theory of engagement (see Thevenot, 2001 for the criticisms). According to Thevenot, people engage with the world in a small number of basic regimes. These regimes are identified by reference to dependencies between "the human being and his or her environment" (Thevenot, 2007, p. 411), have different spatial and temporal horizons (Thevenot, 2013, p. 163), and encompass different pairings of form of coordination with self and form of coordination with others. These regimes conjointly enable the composition of personality and the construction of community, that is, sociality. Moreover, both an integrated personality and an integrated community require successful involvement in all the regimes. Hence, through the engagement of individual human beings with their environments, both persons and communities are coordinately built.

Each regime of engagement encompasses, inter alia, (1) an active relation to and form of dependency on some environment, (2) a good that engagement with that environment should attain, and (3) a specific mastery, which is an agent's power to maintain the engagement, including preserve the environment on which it depends. Each regime also sustains a form of mutual engagement, that is, the form of sociality that results when multiple people are involved in it. There are three basic regimes (a fourth, introduced later, will be bracketed here).

The first regime is that of familiar engagement. The environment it encompasses is a person's immediate, familiar human and material surroundings. The good pursued in this regime is convenience and feeling at ease, and the form of dependency involved is the 
security and affinity of acting in familiar surroundings. Coordinately, a person's mastery is facility in maintaining familiarity, intimacy, and a familiar, intimate environment. Mutual engagement, finally, takes the forms of love, caring, and friendship. These relationships permit only limited coordination, that is, only limited numbers of people can maintain particular relationships of these kinds and form intimate societies. Note that the environment involved in this first regime is not whatever immediate human and material surroundings a person is in, but only those surroundings of this sort that are familiar and intimate, thus, above all such locales as the household or the workplace, though in principle any immediate setting could qualify.

The second regime is the regime of engagement in a plan. It encompasses what most people would think of as normal action (Thevenot, 2007, p. 417). The good of this regime is "the felicitous exercise of the will by an individual endowed with autonomy and capable of projecting herself successfully into the future" (ibid, italics removed), that is, "the autonomy of the bearer of an individual plan.” (2013, p. 163). The form of dependency and mastery involved are, respectively, relying on the world in the pursuit of one's intentions and plans and the ability to use the environment in this pursuit. Mutual engagement takes the form of joint plans or projects, which allows for coordination with greater numbers of people than do love, caring, and friendship. No particular environments are implicated in this regime. Rather, those engaged in it encounter a functionalized world that assists or hinders intentions and plans; the spatial-temporal scope of relevant worlds varies from intention to intention, plan to plan.

The third regime is that of justifiable action, or of engagement justified by the common good. It encompasses the legitimate orders of worth that Thevenot conceptualized with Boltanski (2007) to capture the variety of ways that disputes and arguments in public can be settled by reference to justifications based on principles or conventions of worth. The goods in this regime (common goods) are the different principles or conventions of worth at work in these orders, for example, market price or competition, efficiency, renown, civic solidarity, domestic trust, and inspiration. Mastery, meanwhile, is the enjoyment of authority and power vis-à-vis disputes and interactions based on the possession of qualities in these registers that qualify one as a person of a certain type: dealer, expert, celebrity, citizen etc. Mutual engagement, finally, takes the form of criticizable coordination in the 
public domain on the basis of conventions that embody these principles of worth and are backed up by individuals of authority and power who cite them. Thevenot writes that the regime of engagement in a plan - the world of "individualization, interests, strategies, and negotiations"-occurs "below" that of engagement justified by the common good. What he means, I think, is that the numbers and space-time spread of people who can be coordinated by norms of worth are greater than those who can be joined in joint plans and projects.

When a person is invested in all three regimes, she has some degree of power to maintain intimacy and familiarity and to achieve plans (using the world to that end), and enjoys some authority in the public domain. She also feels at ease, is satisfied through the accomplishment of plans, and achieves/upholds principles or conventions of worth. She has friendships and love relations, participates in joint projects, and settles public disputes through justifications based on these principles or conventions. Her personality is integrated, and she achieves continuity over time, at the same time as different forms of community or sociality are instituted and perpetuated. Persons and social formations are achieved conjointly.

This seems like an exciting position that posits the existence of processes and mechanisms by virtue of which individuals and social formations jointly emerge. If this were true, Thevenot's position would not be individualist in character. It would instead resemble theories that use Karen Barad's (2007) idea of intra-agency to theorize the joint institution in some third thing-apparatuses, or material-discursive practices, in Barad-of the two sides of a traditional dualism, e.g., the agency of humans and of nonhumans (Gherardi, 2017), scientific knowledge and its object (Rouse, 2003), or matter and meaning (Barad, 2007). Thevenot would be envisioning the joint institution of people and community in a third thing, namely, regimes of engagement. It is true that Thevenot seems to pull back from this more radical vision, (re)assuring his readers that regimes are socialand thus possibly lie on one side of the dualism involved-because they guarantee coordination with others (2013, p. 175), involve relations to others (2014, p. 9), or are common (2001, p. 67) or commonly acknowledged (2014, p. 15). However, the first two of these characterizations simply reiterate that sociality results from the regimes, whereas the third is too undifferentiated: emotion and teleology, like human nature and la condition humaine, are common to people but not thereby social in nature. The idea that regimes are 
a sort of third thing out of which people and communities, people and practices, emerge, is still plausible.

Alas, appearances are deceiving. This clearly emerges when Thevenot writes that coordination with oneself ("from one moment to the next;" 2001, p. 66) underlies coordination with others: "instead of focusing on subjects or constraints, to focus on engagement reveals the formation of personalities as well those things generating human community, beginning with the self-investment that jointly secure the maintenance of both." (2013, p. 175) The account of regimes of engagement enlarges "the notion of coordinative powers to personal capacities or abilities that imply coordination with oneself and are a prerequisite for coordination with others." (2014, p. 11) Thevenot's idea is that the powers individuals acquire in these regimes, which are described as a form of coordination with oneself, underlie the forms of coordination with others that are effected in these regimes. For "such self-coordination has to be drawn upon to form expectations about someone else's course of action when coordinating with others.” (ibid). Thevenot's account of regimes prioritizes coordination with oneself and bases coordination with others on this.

It turns out, therefore, that Thevenot's account is individualist. Not only is community built up through achievement of coordinations among people, but the build-up of community presupposes the existence of people capable of doing this. Indeed, Thevenot claims that coordination with others is "always problematic" (2007, p. 413). He thereby ignores the commonalities-e.g., bundles, including practice organizations-that are involved both whenever coordination is achieved among individuals and in the coming about of people capable of coordinating. Thevenot is right that "coordination can neither be reduced to an order controlled by social norms or maintained by market equilibrium" nor ensured by "habits shared through the alignment of social practices." (2013, p. 165) But this does not mean that other forms of commonality are absent or that citing them "defines away the problem of coordination" (ibid). Indeed, Thevenot himself makes commonality essential to coordination: common regimes, common goods, and common orders of worth.

Though I cannot elaborate the matter presently, I must add that the idea that "coordination with self" underlies coordination with others runs counter to much philosophical thought in recent decades. Wittgenstein, for example, undercut the longstanding idea that knowledge of one's own mind underlies knowledge of others', unearthing 
the conceptual problems with this claim, showing that the two knowledges develop in tandem, and calling attention to the existence of perceptional knowledge of other minds. For ittgenstein, it is not necessary to draw on self-knowledge to form expectations about others: one can form these expectations on the basis of one's experiences of others and what one learns about them. Thevenot signals that he knows he is swimming philosophically upstream when he bemoans that " $[t]$ he large movement of reduction of the notion of usage to what makes sense in public space assumes an anthropology founded on speech and visual perception' (2014, p. 15). More pertinent to the present discussion, he argues that "close engagements (in familiarity...) depend on a kind [of] idiosyncratic hold on the environment..." and "do not allow the kind of commonality that is assumed by current notions of (collective) practices or interactions." I agree that a person's experience of her intimate, familiar environment can be idiosyncratic, though I doubt that all holds on the environment in the regime of familiarity are such. But this fact does not automatically vitiate theories of practice and the notions of commonality they develop since, as indicated, these theories can acknowledge that experience occurs on the background of bundles and can be grasped only by a conceptual apparatus that is other than, but complementary to, that of practice theory (e.g., Dreier's account of the person).

As discussed above, practice theory holds that there come to be people involved in Thevenot's regimes by virtue of humans participating in practices. For instance, there come to be individuals who relate to familiar, intimate environments (in forms warranting the epithet "self-coordination") and who form bonds of friendship and love, only through inauguration into and the learning of practices and bundles (see Scollon, 2001). It is not clear to me how on Thevenot's account there come to be people able to participate in the regimes. Like ontogenesis, furthermore, forms of coordination among people are embedded in and depend on bundles (see Schatzki, 2010 for discussion and illustration). People, for example, don't need to (re)invent the ties of love and friendship they take up when relating to the world in the first regime of engagement. Actual and possible forms of love and friendship are already available in extant practices whenever a particular individual comes to form such ties, and the particular ties he takes up largely mirror the available forms, which fact does not exclude the possibility of idiosyncrasy and innovation. Similarly, actual and possible ways of arranging and relating to intimate environments and their components are 
already available in extant practices whenever a person comes to inhabit such an environment (contrast Thevenot, 2001, p. 62). These claims do not imply that practices are solely responsible for all dimensions of coordination. People contribute to coordination, too. The point is, instead, that coordination requires both people and practices. This is true of social affairs generally.

This essay has explored the relationship between people and practices. Its central claims are that both people and practices are real, that these realities interact and are mutually dependent, and that people and practices alike contribute to most aspects of social existence. Social theory must not neglect practices for individuals or individuals for practices but instead explore their mutual dependence and joint construction of social life. 


\section{References}

Alkemeyer, T., (2013). Subjektivierung in sozialen Praktiken. Umrisse einer praxeologischen Analytik. In T. Alkemeyer \& G. Budde (Ed.), Selbst-Bildungen: Soziale u. kulturelle Praktiken der Subjektivierung. Bielefeld, transcript, 33-68.

Alkemeyer, T., \& Buschmann, N. (2017). Learning in practices: enablement in-between selfmaking and subjectivation. In A. Hui, T. R. Schatzki, \& E. Shove (Eds.), The nexus of practices: connections, constellations, practitioners. Abingdon, Routledge, 8-23.

Alkemeyer, T., Buschmann, N., \& Michaeeler, M. (2016). Arguments for a subjectivation theoretical expansion on practice theory. In M. Jonas, \& B. Littig (Eds.), A praxeological political analysis. Abindgon, Routledge, 67-83.

Archer, M. S. (1995). Realist social theory: the morphogenetic approach. Cambridge, Cambridge University Press.

Barad, K. (2007). Meeting the universe halfway: quantum physics and the entanglement of matter and meaning. Durham, Duke University Press.

Billet, S. (2001). Learning through work: workplace affordances and individual engagement. Journal of Workplace Learning, (13)5, 200-214.

Billet, S. (2006). Relational interdependence between social and individual agency in work and working life. Mind, Culture, and Society, (13)1, 53-69.

Billet, S. (2009). Conceptualizing learning experiences: contributions and mediations of the social. Personal and brute. Mind, Culture, Society, 16, 32-47.

Boltanski, L., \& Thevenot, L. (2007) [1991]. On justification: economies of worth. Princeton, Princeton University Press.

Bourdieu, P. (1990). The logic of practice. Richard Nice (tr), Cambridge, UK, Polity Press.

Collins, R. (2004). Interaction ritual chains. Princeton, Princeton University Press. 
Dall'Alba, G. (2009). Learning to be professionals. Springer, Berlin.

Dall'Alba, G. \& Sandberg, J. (2010). Learning through and about practices: a lifeworld perspective. In S. Billett (Ed.), Learning through practice. Berlin, Springer, 104-19.

Dreier, O. (1999). Personal trajectories of participation across contexts of social practice. In Outlines: Critical Social Studies, 1, 5-32.

Dreier, O. (2007). Psychotherapy in everyday life. Cambridge, Cambridge University Press.

Dreier, O. (2009). Learning in structures of social practice. In K. Nielson, et al. (Eds.), $A$ qualitative stance: essays in honor of Steinar Kvale. Aarhus, Aarhus University Press, 8596.

Gergen, K.J. (1995). Singular, socialized and relational selves. In I. Lubek, R. Hazewijk, G. Pheterson, \& C. Tolman, (Eds.), Trends and issues in theoretical psychology. New York: Springer-Verlag.

Gherardi, S. (2017). Sociomateriality in post-humanist practice theory. In A. Hui, T. R. Schatzki, \& E. Shove (Eds.), The nexus of practices: connections, constellations, practitioners. Abingdon, Routledge, 38-51.

Giddens, A. (1979). Central problems in social theory: action, structure, and contradiction in social analysis. Berkeley, University of California Press.

Laclau, E., \& Mouffe, C. (1985). Hegemony and socialist strategy: toward a radical democratic politics. London, Verso.

Maller, C. (2017). Epigenetics, theories of social practice and lifestyle disease. In A. Hui, T. R. Schatzki, \& E. Shove (Eds.). The nexus of practices: connections, constellations, practitioners. Abingdon, Routledge, 68-80.

Pickering, A. (1995). The mangle of practice: time, agency, and science. Chicago, University of Chicago Press. 
Reckwitz, A. (2002). Toward a theory of social practices. A development in culturalist theorizing. European Journal of Social Theory, 5(2): 243-63.

Reckwitz, A. (2006). Das hybride Subjekt. Eine Theorie der Subjektkulturen von der bürgerlichen Moderne zur Postmoderne, Stuttgart, Velbruk Wissenschaft.

Reckwitz, A. (2016). Practices and their affects. In A. Hui, T. R. Schatzki, \& E. Shove (Eds.), The nexus of practices: connections, constellations, practitioners, Abingdon, Routledge, $114-25$.

Roepstorff, A., Niewöhner, J., \& Beck, S. (2010). Enculturing brains through patterned practices. Neural Networks, 23, 1051-59.

Rouse, J. (2001). Two concepts of practices. In T. R. Schatzki, K. Knorr Cetina, \& E. von Savigny (Eds.), The Practice Turn in Contemporary Theory. London, Routledge, 189-98.

Rouse, J. (2003). How scientific practices matter: reclaiming philosophical naturalism. Chicago, University of Chicago Press.

Schatzki, T. (1996). Social practices: a wittgensteinian approach to human activity and the social. New York, Cambridge University Press.

Schatzki, T. (2002). The site of the social: a philosophical exploration of the constitution of social life and change. University Park, the Pennsylvania State University Press.

Schatzki, T. (2010). The timespace of human activity: performance, society, and history as indeterminate teleological events. Lanham, MD, Lexington Books.

Schatzki, T. (2013). The edge of change: on the emergence, persistence, and dissolution of practices. In E. Shove, \& N. Spurling (Eds.), Sustainable practices. Social theory and climate change. Abingdon, Routledge, 31-46.

Schatzki, T. (2016). Tracking Large Phenomena. Geographische Zeitschrift, 104(1), 4-24.

Scheff, T. (1988). Shame and conformity: the deference-emotion system. American Sociological Review, 52, 395-406. 
Scollon, R. (2001). Mediated discourse. The nexus of practice, New York, Routledge.

Strawson, P. (1959). Individuals. London, Methuen.

Thevenot, L. (2001). Pragmatic regimes governing the engagement with the world.” In T. R. Schatzki, K. Knorr Cetina, \& E. von Savigny (Eds.), The Practice Turn in Contemporary Theory. London, Routledge, 56-73.

Thevenot, L. (2007). The plurality of cognitive formats and engagements. Moving between the familiar and the public. European Journal of Social Theory, 10(3), 409-23.

Thevenot, L. (2013). The human being invested in social forms. Four extensions of the notion of engagement. In M. S. Archer \& A. Maccarini (Eds.), Engaging with the world: agency, institutions, historical formations.. Abingdon, Routledge, 162-180.

Thevenot, L. (2014). Voicing concern and difference: from public spaces to common-places. European Journal of Cultural and Political Sociology, 1(1), 7-34.

Turner, S. (2002). Brains/practices/relativism: social theory after cognitive science. Chicago, University of Chicago Press.

Weenink, D., \& Spaargaren, G. (2017). Emotional agency navigates a world of practices. In G. Spaargaren, D. Weenink \& M. Lamers (Ed.), Practice theory and research: exploring the dynamics of social life. Abingdon, Routledge 6o-84.

\footnotetext{
i Two principal exceptions to this generalization are Dreier, e.g., 2007 and Alkemeyer, e.g., 2013. See also the discussions of mind/action in Schatzki 1996, 2010.

ii Notice that the grammatical concept of a subject as that of which something is predicated converges with the Strawsonian concept of the person I advocate. It is a good issue, extensively debated in contemporary thought, what must be attributable to something in order for it to count as a person.

iii For parallel ideas oriented toward understanding the conduct of a life, life trajectories, and learning, see Dreier 1999, 2007.

iv Many entities are said to learn, including human persons, animals, computers, organizations, and societies. Because the focus of this essay is on human persons, I set aside issues about whether and, if so, what it is for entities of these other types to learn.

$\mathrm{v}$ I think, though am not sure, that similar remarks apply to teleology: teleology, too, is a basic feature of existence to which the edifice of bundles is connected.
} 